\title{
Can Gold Hedge Stock Market and Inflation Simultaneously?
}

\author{
Jiaming Chen ${ }^{1}$ \\ ${ }^{1} \mathrm{PhD}$ School and Department of Economics, Bocconi University, Milan, Italy \\ Correspondence: Jiaming Chen, PhD School and Department of Economics, Bocconi University, Milan, MI, Italy. \\ Tel: 39-349-849-7578. E-mail: jiamingchn@gmail.com
}

Received: February 6, 2020

Accepted: February 29, 2020

Online Published: March 5, 2020

doi:10.5539/ijef.v12n4p1

URL: https://doi.org/10.5539/ijef.v12n4p1

\begin{abstract}
The hedging property of gold against single asset has been greatly demonstrated in literature. Gold-stock hedge suggests gold as 'safe haven' for stock market. Unlike gold-stock hedge which requires zero or negative correlation between their returns, gold-inflation hedge refers to the positive co-movement or 'peg' between gold return and inflation. Thus, this is the first paper to address whether gold can hedge stock market and inflation simultaneously since stock market boom often comes with moderate inflation which creates puzzle in gold price dynamics and its hedging property. In this paper, we assume that an investor creates optimal portfolios from stock and gold. The weights assigned to gold are interpreted as hedge coefficient towards the stock market. We ask if the hedge coefficient also moves in tandem with inflation or other functions of inflation. When regressing the hedge coefficient on inflation or functions of inflation, the slope will be positive if the gold first used to hedge the stock market can also hedge inflation. We find that is not the case: the coefficient is not positive in statistics. This result implies that gold fails to hedge both stock market and inflation simultaneously over time.
\end{abstract}

Keywords: gold, hedging, portfolio and asset allocation

JEL Codes: B4, G1.

\section{Introduction}

\subsection{Introduce the Problem}

Hedge is a risk management tool frequently exercised by investors and institutions. One of the products widely used for hedging purpose is gold and its derivatives, and this fact has been widely recognized and documented by both professional practice and academic research (Emmrich \& McGroarty, 2013; Lucey \& Li, 2015; Areal, Oliveira, \& Sampaio, 2015 etc). In some literature, gold is also named as 'safe haven' asset (Baur and McDermott, 2010). When gold is used to hedge stock market like SP500, the concept of 'safe haven' refers to the zero or negative correlation between gold and stock market's returns. However, not all hedging property of gold imply low or negative correlation between assets' returns. For instance, gold-inflation hedge is motivated by the intrinsic value of gold which requires positive co-movement or 'peg' between gold return and inflation rate.

This paper works on the hedging property of gold. However, instead of focusing on the hedging property of gold against a single asset or single variable which has been well explored, we visit a potential puzzle and ambiguity which has not been explained and verified from any previous work to the best of our knowledge. This puzzle is, can gold simultaneously hedge stock market and inflation, consider inflation rise often goes against stock fall which creates unclear dynamics of gold prices on those moments?

One difficulty of addressing this puzzle in terms of empirical exercise is about how to address the issue of simultaneity. We develop and provide a new approach and framework to this issue and similar problem in this paper. We first assume that an investor creates optimal portfolios from stock and gold. The weights assigned to gold are interpreted as hedge coefficient towards the stock market. Then we ask if the hedge coefficient also moves in tandem with inflation or other functions of inflation. When regressing the hedge coefficient on inflation or functions of inflation, the slope will be positive if the gold 'first' used to optimally hedge the stock market can still hedge inflation. In other words, this approach tries to verify whether gold can still hedge inflation conditional on assuming investors have optimally used it to hedge stock market on the same moment. In this paper, we find that is not the case: there is no statistical evidence to support positive relationship between inflation or proxy of gold-inflation hedging and hedging coefficients measured by weights of gold in gold-stock portfolio. 
We need to pinpoint this paper doesn't study the average hedging effect of gold against both stock market and inflation in the long run which could be well estimated by a line of multi-variate regression. However, we do employ such a multi-variate regression as a baseline model for comparison to better illustrate such a difference. In fact, over the long run period from 1985 to 2019, the results of regression for comparison suggest that investors can hedge both equity market and inflation together if they keep holding gold over the complete time horizon without any action of selling or re-balancing. Opposite but not contradictory to the results of comparison, the new approach developed in this paper concludes that under the context of trading or re-balancing gold and its weight in portfolio actively with monthly frequency, investors or portfolio managers are unable to hedge both inflation and stock market efficiently in the simultaneous content.

\subsection{Literature Review}

Evidence of gold's hedge against various assets and economic variables including stock and inflation could be found in abundant literature. Stock-gold relation is relatively clear and straightforward. Zero or negative correlation in stock-gold returns caused by flight to quality has been solidly examined (Baur \& Lucey, 2010). Based on this fact, most studies agree that gold can serve as a good hedge or safe haven when stock market falls even though occasionally such effect is limited and insignificant (Choudhry, Hassan, \& Shabi, 2015). Gold can also hedge (rising) inflation because it has intrinsic value driven by its limited supply as a prestitous metal. Worthington and Pahlavani (2007) give cointegration evidence by allowing for endogenous structural break and appoint gold investment as effective inflation hedge. From the perspective of macroeconomic news releases, David, Chaudhry, and Koch (2000) find gold responds strongly to the release of the CPI. However, the inflation-gold relation might be not as obvious as stock-gold. Beckmann and Czudaj (2013) suggest that gold's inflation hedge crucially depends on the time horizon. Lucey et al. (2014) suggest that gold's sensitivity to inflation relies on interest rate changes. For instance, expected inflation rise usually brings higher expected interest rate which may depress gold prices and twist its hedging effect against inflation (Fortune, 1987).

Here comes the puzzle. As gold return usually increases with respect to the fall in stock return which triggers gold-stock hedge, and gold return increases in response to rising inflation which refers to gold-inflation hedge; what will happen if both inflation rise and stock market boom occur on the same moment? Will gold prices still increase in response to rising inflation? Or gold prices may decrease or just barely increase because the stock market performs outstandingly well? Project this puzzle to an investment question, we know gold can hedge inflation and equity market separately, but can gold hedge both simultaneously? Such a puzzle and ambiguity haven't been addressed in any previous study to the best of our knowledge, and this becomes the motivation and main research question in this paper. In terms of practical meaning, this puzzle is particularly interesting and attractive to investors and institutions since inflation rise and stock market boom frequently come together (Kaul, 1987; William, Huang, \& Wang, 2016).

\subsection{Model of Comparison and Motivation}

Most researches working on hedging property of gold use time series techniques such as ARMA, GARCH, and VAR. Those works follow similar patterns, like regressing the returns of gold on variable of interest to verify statistical evidence. However, those common methods we have seen so far in previous studies may not work well for solving the puzzle we propose in this paper. The reason has been pointed out earlier: previous studies analyze the hedging property of gold on a single asset or product like stock or inflation while this paper tries to find if gold can hedge both stock market and inflation simultaneously. In other words, we concern about whether gold could still hedge inflation on exact same moment when it is used to hedge stock market optimally 'first'. Such scenario brings a problem if we only apply a multi-variate regression by regressing gold return on both stock market return and inflation rate since the estimated parameters (beta) can only explain the 'local average effect' of explanatory variables over sample. Thus, multivariate regression does provide evidence about the average hedging effect of gold on both stock market and inflation with a much more general meaning.

In order to better highlight such a difference, this paper also employs a multi-variate regression as a benchmark model of comparison to estimate the long-run average hedging effect of gold against both inflation and stock market. The baseline regression, or say the model of comparison, regresses return of gold on stock market (SP500) return and inflation rate measured by the growth of CPI. Necessary controls include the value of US dollar, interest rate, dummy variables for decades, and dummy variable for recession periods defined by NBER. All the variables are of monthly frequency, based on the case of the United States, and taken from Federal Reserve Economic Data (FRED). 


$$
\begin{aligned}
& \mathrm{r}_{g, t}=\beta_{1} r_{s p, t}+\beta_{2} \pi_{t}+\beta_{3} \text { dollar_value }+\beta_{4} \text { interest_rate }+\beta_{5} \text { dummy_recession } \\
& \quad+\beta_{6} \text { dummy_19851995 }+\beta_{7} \text { dummy_19952005 }+\beta_{8} \text { dummy_20052015 }+\alpha
\end{aligned}
$$

Table 1. Descriptive statistics

\begin{tabular}{lccccccc}
\hline Statistic & $\mathrm{N}$ & Mean & St. Dev. & Min & Pctl(25) & Pctl(75) & Max \\
\hline Return of SP500 & 412 & 0.669 & 4.320 & -24.543 & -1.699 & 3.455 & 12.378 \\
Return of gold & 412 & 0.350 & 3.500 & -12.391 & -1.688 & 2.324 & 16.387 \\
Portfolio weight of gold & 411 & 0.547 & 0.334 & 0.001 & 0.250 & 0.882 & 0.999 \\
Inflation_seasonal_adjusted & 413 & 0.214 & 0.253 & -1.771 & 0.106 & 0.345 & 1.377 \\
Dollar value & 413 & 99.269 & 20.558 & 58.643 & 84.242 & 116.115 & 129.640 \\
Interest rate & 413 & 3.612 & 2.800 & 0.070 & 0.970 & 5.560 & 9.850 \\
\hline
\end{tabular}

Table 1 summaries the variables employed in this paper. The 'portfolio weight of gold' is computed in the next section. It is the weight assigned to gold in optimized gold-stock portfolio, and it is further used as the proxy for gold-stock hedging or say hedge coefficient. We further regress such hedge coefficients on inflation and the proxy of gold-inflation hedge to examine the issue of simultaneous hedge.

The estimates of baseline multi-variate regression (1) are shown in table 2. The results well capture the overall hedging effect of gold against both stock market and inflation in the long run. Like previous literature suggest, gold could not only hedge inflation, but also hedge expected/leading inflation or the change in inflation. For gold-stock hedging, the estimation for gold's hedging against equity market represented by SP500 is statistically significant at 0.01 level, and the estimated coefficient is about -0.175 to -0.18 which implies that 1 percent increase in SP500 return is associated with 0.18 percent decrease in gold return, keep other variables constant. The negative relation between gold and stock market returns ensures gold to play the role of 'variance reducer' and 'safe haven' against stock market, and such result is robust. Compared with gold-stock hedge, the gold-inflation hedge estimated by baseline regression is not as clear in statistics, which also matches the finding of relevant literature. One interesting fact is that when we include both inflation and inflation change $\left(1^{\text {st }}\right.$ difference in inflation) in the regression, the inflation change greatly takes the explanatory power away from the inflation, though the estimate for SP500 doesn't vary in any meaningful way. This fact somehow suggests that gold price may react to the 'change in inflation' more sensitively, or at least some particular intertemporal patterns in gold's hedge against inflation exist.

\begin{tabular}{|c|c|c|c|c|}
\hline & \multicolumn{4}{|c|}{ Dependent variable: } \\
\hline & \multicolumn{4}{|c|}{ Return of gold } \\
\hline & $(1)$ & $(2)$ & $(3)$ & (4) \\
\hline Return of SP500 & $\begin{array}{c}-0.176^{* * *} \\
(0.037)\end{array}$ & $\begin{array}{c}-0.183^{* * *} \\
(0.037)\end{array}$ & $\begin{array}{c}-0.177^{* * *} \\
(0.037)\end{array}$ & $\begin{array}{c}-0.175^{* * *} \\
(0.037)\end{array}$ \\
\hline Inflation (seasonal adjusted) & $\begin{array}{l}1.445^{* *} \\
(0.671)\end{array}$ & & & $\begin{array}{c}0.736 \\
(0.789)\end{array}$ \\
\hline Leading inflation & & $\begin{array}{c}0.513 \\
(0.658)\end{array}$ & & \\
\hline Change in inflation & & & $\begin{array}{l}1.519^{* *} \\
(0.587)\end{array}$ & $\begin{array}{l}1.177^{*} \\
(0.692)\end{array}$ \\
\hline US dollar & $\begin{array}{c}-1.163^{* * *} \\
(0.131)\end{array}$ & $\begin{array}{c}-1.207^{* * *} \\
(0.131)\end{array}$ & $\begin{array}{c}-1.164^{* * *} \\
(0.129)\end{array}$ & $\begin{array}{c}-1.145^{* * *} \\
(0.131)\end{array}$ \\
\hline Interest rate & $\begin{array}{c}0.004 \\
(0.015)\end{array}$ & $\begin{array}{c}0.011 \\
(0.014)\end{array}$ & $\begin{array}{c}0.011 \\
(0.014)\end{array}$ & $\begin{array}{c}0.007 \\
(0.015)\end{array}$ \\
\hline Dummy of recession & $\begin{array}{c}0.125 \\
(0.603)\end{array}$ & $\begin{array}{c}0.201 \\
(0.606)\end{array}$ & $\begin{array}{c}0.162 \\
(0.601)\end{array}$ & $\begin{array}{c}0.136 \\
(0.602)\end{array}$ \\
\hline Dummy of $1985-1995$ & $\begin{array}{l}-0.229 \\
(0.577)\end{array}$ & $\begin{array}{l}-0.075 \\
(0.578)\end{array}$ & $\begin{array}{l}-0.013 \\
(0.567)\end{array}$ & $\begin{array}{l}-0.125 \\
(0.579)\end{array}$ \\
\hline Dummy of 1995-2005 & $\begin{array}{l}-0.299 \\
(0.575)\end{array}$ & $\begin{array}{l}-0.223 \\
(0.577)\end{array}$ & $\begin{array}{c}-0.196 \\
(0.572)\end{array}$ & $\begin{array}{l}-0.248 \\
(0.575)\end{array}$ \\
\hline Dummy of 2005-2015 & $\begin{array}{c}0.074 \\
(0.581)\end{array}$ & $\begin{array}{c}0.106 \\
(0.584)\end{array}$ & $\begin{array}{c}0.106 \\
(0.579)\end{array}$ & $\begin{array}{c}0.090 \\
(0.580)\end{array}$ \\
\hline Constant & $\begin{array}{c}0.469 \\
(0.507)\end{array}$ & $\begin{array}{c}0.597 \\
(0.512)\end{array}$ & $\begin{array}{c}0.672 \\
(0.497)\end{array}$ & $\begin{array}{c}0.567 \\
(0.510)\end{array}$ \\
\hline Observations & 411 & 411 & 411 & 411 \\
\hline $\mathrm{R}^{2}$ & 0.214 & 0.206 & 0.218 & 0.220 \\
\hline Adjusted $\mathrm{R}^{2}$ & 0.198 & 0.190 & 0.202 & 0.202 \\
\hline Residual Std. Error & 3.137 & 3.153 & 3.129 & 3.130 \\
\hline F Statistic & $13.681^{* * *}$ & $13.048^{* * *}$ & $14.003^{* * *}$ & $12.540^{* * *}$ \\
\hline
\end{tabular}

Table 2. OLS estimate of comparison model

Note. ${ }^{*} \mathrm{p}<0.1 ; * * \mathrm{p}<0.05 ; * * * \mathrm{p}<0.01$. 
Based on the results of baseline regression, we conclude that gold can hedge both stock market and inflation in the long run even though gold-inflation hedging is a bit ambiguous. However, these estimates don't address the puzzle about simultaneity in a proper way due to the limited interpretation of 'local average effect' as explained earlier.

In the following section, we develop a new approach to empirically examine if investors could actively use gold to hedge both inflation and equity market in a simultaneous content by allowing active trading or re-balance portfolio continuously with monthly frequency. The finding of new approach doeesn't suggest any positive or any meaningful relation between gold-stock and gold-inflation hedging in statistics. Hence, gold fails to hedge stock market and inflation simultaneously. This implication is opposite but not contradictory to baseline regression estimates of comparison.

\section{Method}

This paper concentrates on the case of the United States like most other relevant studies do. All variables except gold price are obtained from Federal Reserve Economic Data (FRED). Data of gold price is taken from World Gold Forum. Based on the scope of our research question, monthly data starting from 1985 January to 2019 May is used. One main reason we use monthly data is that asset allocation or portfolio adjustment is frequently exercised by month or quarter in real world. The main variables include prices of gold, stock market index quoted by SP500, and consumer price index. We take standard process of the following

$$
r_{t}=100 * \log \left(P_{t} / P_{t-1}\right)
$$

to compute gold return, stock market return, as well as inflation rate. The exogeneous controls include interest rate, dollar index, dummy for decades, and dummy for U.S. recession as we illustrated earlier. All employed variables are stationary.

In order to address the issue of simultaneity, our approach includes two stages. The first stage is to compute the hedge coefficient of gold against stock market. More precisely, we compute the degrees or magnitudes that gold hedges stock market by solving Markowitz's portfolio optimization problem. In this way, the hedge coefficient of gold against stock is measured by the solved weights of gold in gold-stock portfolio over time, which can also be regarded as the proxy for gold-stock hedging. In the second stage, we regress the hedge coefficient obtained from first stage on inflation or the proxy of gold-inflation hedge to verify whether the gold-stock hedge (the weights assigned to gold in gold-stock portfolio) moves in tandem with the dynamics of inflation or not.

We first compute the weights assigned to gold in optimized gold-stock portfolio by solving Markowitz portfolio problem (1952). The allocated weights to gold can be computed through optimizing the portfolio by maximizing Sharpe ratio of the portfolio as following,

$$
\max _{w_{g, t}} \frac{r_{p, t}-r_{f, t}}{\sigma_{p, t}}
$$

where

$$
\begin{gathered}
r_{p}=w_{g} r_{g}+\left(1-w_{g}\right) r_{s p} \\
\sigma_{p}^{2}=w_{g}^{2} \sigma_{g}^{2}+\left(1-w_{g}\right)^{2} \sigma_{s p}^{2}+2 w_{g}\left(1-w_{g}\right) \sigma_{g} \sigma_{s p} \rho_{g, s p}
\end{gathered}
$$

In order to compute the dynamic (non-static) correlation between gold and stock market $\rho_{\mathrm{g} \_ \text {sp }, \text {, }}$ we use a frequent-exercised method, dynamic (conditional) correlation based on GARCH (DCC-GARCH) developed by Robert Engle (2001). We first filter the returns of both gold and stock market index SP500 using ARMA (m,n) process as following to obtain a white noise return series:

$$
r_{i t}=c_{i}+\sum_{j=1}^{m} \beta_{i j} r_{i, t-j}+\sum_{k=1}^{n} \alpha_{i k} z_{i, t-k}+z_{i t}
$$

where $\mathrm{i}=1,2$ corresponding to gold and SP500.

Then we extract residual vector consisting of the fitted return obtained from the two ARMA processes

$$
Z_{t}=\left[z_{1 t}, z_{2 t}\right]^{\prime} \quad Z_{t} \mid \Omega_{t} \sim N\left[0, H_{t}\right]
$$


where $\Omega_{\mathrm{t}}$ is the information set at moment t. $\mathrm{H}_{\mathrm{t}}$ can be written as

$$
H_{t}=D_{t} R_{t} D_{t}
$$

where

$$
D_{t}=\operatorname{diag}\left(H_{t}\right)=\operatorname{diag}\left(h_{1 t}^{1 / 2}, h_{2 t}^{1 / 2}\right)
$$

Here $D_{t}$ is the $2 X 2$ diagonal matrix of (conditional) standard deviations of fitted return at moment $t$, and $R_{t}$ is the $2 \mathrm{X} 2$ (conditional) correlation matrix of fitted return at moment $t$. We use $\operatorname{GARCH}(1,1)$ to estimate the variances $\mathrm{h}_{1 \mathrm{t}}$ and $\mathrm{h}_{2 \mathrm{t}}$ in matrix $\mathrm{D}_{\mathrm{t}}$.

$$
h_{i t}=w_{i}+\delta_{i} z_{i, t-1}^{2}+\theta_{i} h_{i, t-1}, \quad(i=1,2)
$$

One drawback of computing $\mathrm{w}_{\mathrm{g}, \mathrm{t}}$ through maximizing the Sharpe ratio of constructed portfolio is that many values of computed $\mathrm{w}_{\mathrm{g}, \mathrm{t}}$ turn out to be either 1 or 0 which means that $100 \%$ or $0 \%$ of the portfolio should be in gold on those moments, which complicates the further empirical procedure since the $\mathrm{w}_{\mathrm{g}, \mathrm{t}}$ becomes a binary variable to great extent and such $w_{g, t}$ doesn't make much practical sense in reality either because investors more expect gold to play the rule of 'variance reducer' for stocks in portfolio.

In order to address this defect, we switch to another objective function which is minimizing the variance of portfolio, and it does provide us with much more 'valid' $\mathrm{w}_{\mathrm{g}, \mathrm{t}}$. As figure 1 displays, the weights assigned to gold are quite 'spread out' instead of clustering in 0 or 1 when minimizing portfolio variance.

$$
\min _{w_{g, t}} \sigma_{p, t}^{2}
$$

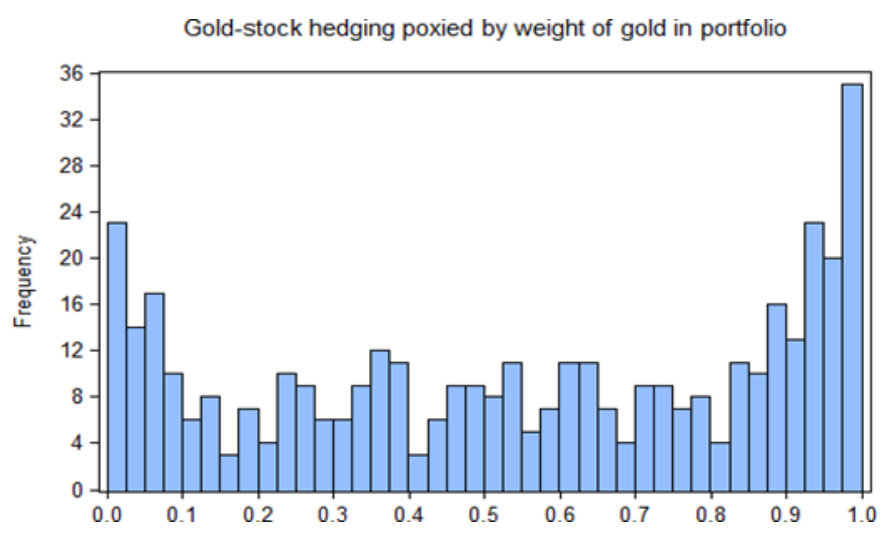

Figure 1. Frequency on weight of gold

Furthermore, based on individuals' risk preference setting or the aim of research question, objective function of portfolio problem can be customerized and corresponding $\mathrm{w}_{\mathrm{g}, \mathrm{t}}$ can be computed differently. For example, one alternative objective function to incorporate maximizing Sharpe ratio with a certain degree of risk aversion can take the form as

$$
\max _{w_{g, t}} \frac{r_{p, t}-r_{f, t}}{\sigma_{p, t}}+f\left(\sigma_{p, t}\right)
$$

and in a greater general form the objective function can be written as

$$
\max _{w_{g, t}} f\left(r_{p, t}, \sigma_{p, t}\right)
$$

As an advantage, the broad availability in the choice of objective function in our approach allows the empirical work to adapt different characteristics of investment and portfolio problem and different prospective of research question. This convenience is one of the highlights of our approach and framework because it empowers and provides tools for relevant research question and further examination in future study.

After the first stage of empirical work, time series weights assigned to gold $\mathrm{w}_{\mathrm{g}, \mathrm{t}}$ which play the proxy for gold-stock hedging or interpreted as hedge coeffieients of gold against stock are collected. In the second stage, 
we regress $\mathrm{w}_{\mathrm{g}, \mathrm{t}}$ on inflation and other form of inflation/gold-inflation hedge to test if the gold-stock hedge coefficients move in tandem with inflation $\pi_{\mathrm{t}}$ and its relevances. We use OLS and the reduced form takes as

$$
w_{\text {gold }}=f(\pi)+X \beta+\epsilon
$$

where $\mathrm{X}$ includes control variables including dollar value, interest rate, and dummies for recession periods and each decade, and $\pi$ is either inflation or the proxy for gold-inflation hedging. In this way, if the estimated slope of $\pi$ is positive in statistics, we can interpret that gold used to hedge stock also hedges inflation on the same moment. Otherwise, gold is unable to hedge both stock market and inflation simultaneously.

As this is a new approach and framework, we employ three specifications for the regression in second stage for comprehensive examination and the consideration of robustness. In first specification, we regress gold-stock hedge coefficients on inflation rate. In second and third specification, we employ two different proxies for gold-inflation hedge and further estimate their relation to gold-stock hedge coefficient (the weights assigned to gold in gold-stock portfolio).

The first proxy for gold-inflation hedging is the dynamic beta of regressing gold return on inflation rate. The dynamic beta is obtained from the process of Kalman filter. The implement algorithm of Kalman filter is not hard to understand. Like the process of autocorrelation, while instead of including an AR term of explanatory variable in regression model, Kalman filter develops the dynamic system with a state space regression modeling the beta dynamics through an autoregressive process. In this way, Kalman filter allows the parameter/estimator of related variable to be time-varying which generates a dynamic parameter in continuous time instead of static parameter. In our framework, the state-space representation of the dynamics of gold-inflation beta (proxy for hedging) is given by the following system of equations

$$
\begin{gathered}
r_{\text {gold }, t}=\alpha+\beta_{t} \pi_{t}+\epsilon_{t} \\
\beta_{t}=T \beta_{t-1}+\delta_{t}
\end{gathered}
$$

where $\beta \mathrm{t}$ is time-varying estimator representing gold-inflation hedging and $\mathrm{T}$ is the state transition matrix.

By using Kalman filter, we collect dynamic estimator as proxy for gold-inflation hedge (see figure 2) and this proxy enables us to verify whether valid relation between gold-stock hedge and gold-inflation hedge exists on the moments along time horizon.

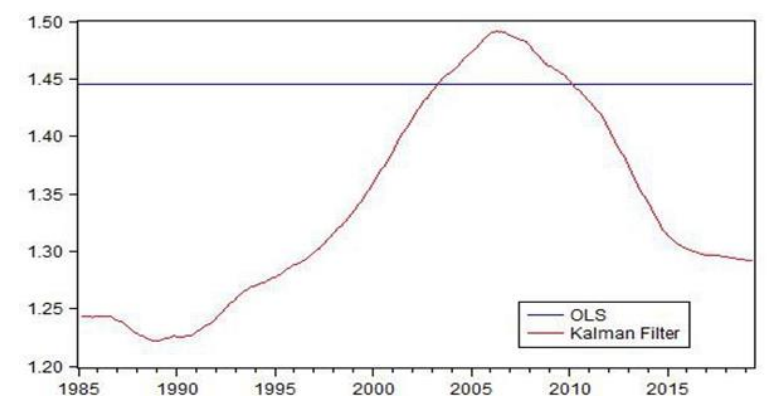

Figure 2. Dynamic beta by Kalman filter

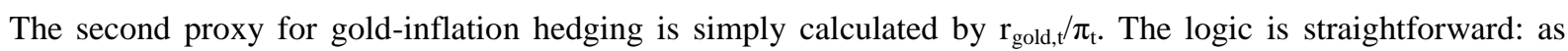
gold-inflation hedge asks positive co-movement or 'peg' between gold price and price level of consumption, greater value of $\mathrm{r}_{\text {gold, } t} / \pi_{\mathrm{t}}$ should represent better 'peg' which indicates more effective hedge of gold against inflation.

\section{Results}

Figure 3 are scatter plots for the relation of gold-stock hedge represented by weight assigned to gold in gold-stock portfolio with respect to inflation, gold-inflation hedge proxied by dynamic beta, and gold-inflation hedge proxied by $r_{\text {gold, },} / \pi_{t}$. From those figures, it is very hard to find any linear or even non-linear pattern in the relation of gold-stock hedge and inflation or its relevance. As a matter of fact, the empirical results of OLS regression do not suggest any positive relation between gold-stock hedge and inflation in statistics. Neither for the two proxies of gold-inflation hedge. 

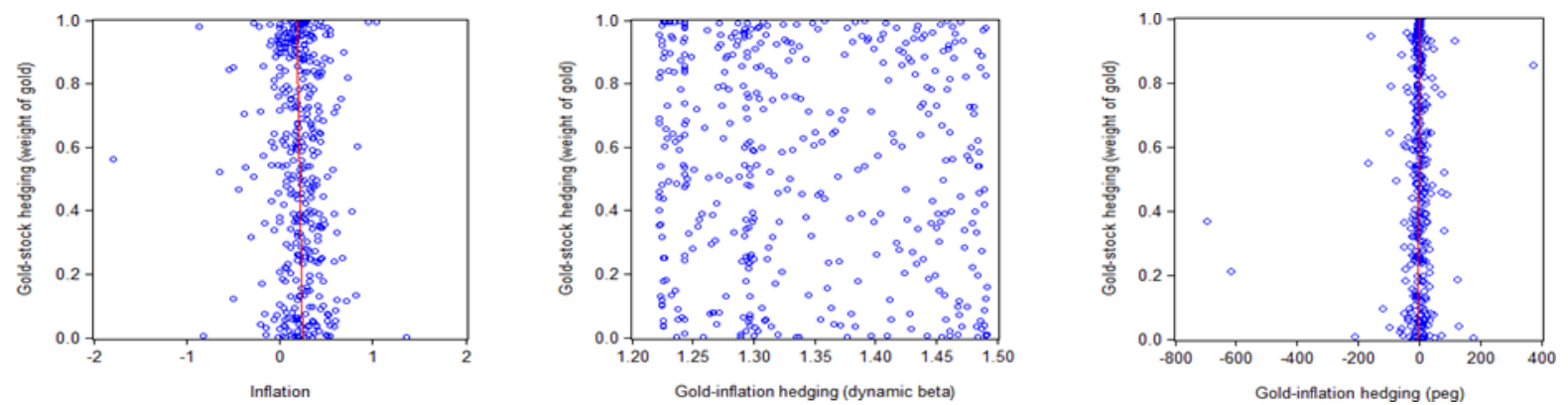

Figure 3. Scatter plot of gold weight in portfolio and inflation

Table 3 summarizes the estimates in the regression of portfolio weight of gold against inflation as well as leading inflation and inflation change. There is no positive slope between weights of gold against SP500 in portfolio and inflation rate which means that positive agreement between gold-stock hedging and inflation is unable to be found. Indeed, the estimated coefficients for inflation and leading inflation are even negative in statistics. In terms of interpretation, around 16 to 18 percentage weight of gold should be even removed from gold-stock portfolio in response to 1 percent increase in inflation or leading inflation holding other variables constant. Of course, the very limited R square of estimated model may not allow such implication to fit well for the reality and population while it is still quite surprising that there is even a negative relation between gold-inflation hedge and gold-stock hedge.

Table 3. OLS regression results

\begin{tabular}{lcccc}
\hline & \multicolumn{4}{c}{ Dependent variable: } \\
\cline { 2 - 5 } & \multicolumn{3}{c}{ Weight of gold against SP500 in portfolio } \\
& $(1)$ & $(2)$ & $(3)$ & $(4)$ \\
\hline Inflation (seasonal adjusted) & $-0.162^{* *}$ & & $-0.152^{*}$ \\
& $(0.070)$ & & $(0.083)$ \\
Leading inflation & & $-0.179^{* * *}$ & & \\
Change in inflation & & $(0.068)$ & & \\
& & & -0.087 & -0.016 \\
US dollar & -0.009 & -0.010 & $(0.062)$ & $(0.073)$ \\
& $(0.013)$ & $(0.013)$ & -0.005 & -0.009 \\
Interest rate & 0.0001 & -0.001 & -0.001 & $(0.013)$ \\
& $(0.002)$ & $(0.002)$ & $(0.002)$ & $(0.0001$ \\
Dummy of recession & 0.077 & 0.062 & 0.071 & 0.077 \\
& $(0.062)$ & $(0.062)$ & $(0.063)$ & $(0.063)$ \\
Dummy of 1985-1995 & $0.142^{* *}$ & $0.141^{* *}$ & $0.118^{* *}$ & $0.141^{* *}$ \\
& $(0.060)$ & $(0.060)$ & $(0.060)$ & $(0.061)$ \\
Dummy of 1995-2005 & $0.144^{* *}$ & $0.142^{* *}$ & $0.132^{* *}$ & $0.143^{* *}$ \\
& $(0.060)$ & $(0.060)$ & $(0.060)$ & $(0.060)$ \\
Dummy of 2005-2015 & -0.010 & -0.014 & -0.013 & -0.010 \\
& $(0.061)$ & $(0.061)$ & $(0.061)$ & $(0.061)$ \\
Constant & $0.492^{* * *}$ & $0.499^{* * *}$ & $0.469^{* * *}$ & $0.491^{* * *}$ \\
& $(0.053)$ & $(0.053)$ & $(0.052)$ & $(0.053)$ \\
\hline Observations & 411 & 411 & 411 & 411 \\
$\mathrm{R}^{2}$ & 0.055 & 0.058 & 0.047 & 0.055 \\
Adjusted $\mathrm{R}^{2}$ & 0.038 & 0.042 & 0.030 & 0.036 \\
Residual Std. Error & 0.328 & 0.327 & 0.329 & 0.328 \\
F Statistic & $3.324^{* * *}$ & $3.563^{* * *}$ & $2.823^{* * *}$ & $2.908^{* * *}$ \\
\hline
\end{tabular}

Note. ${ }^{*} \mathrm{p}<0.1 ; * * \mathrm{p}<0.05 ; * * * \mathrm{p}<0.01$.

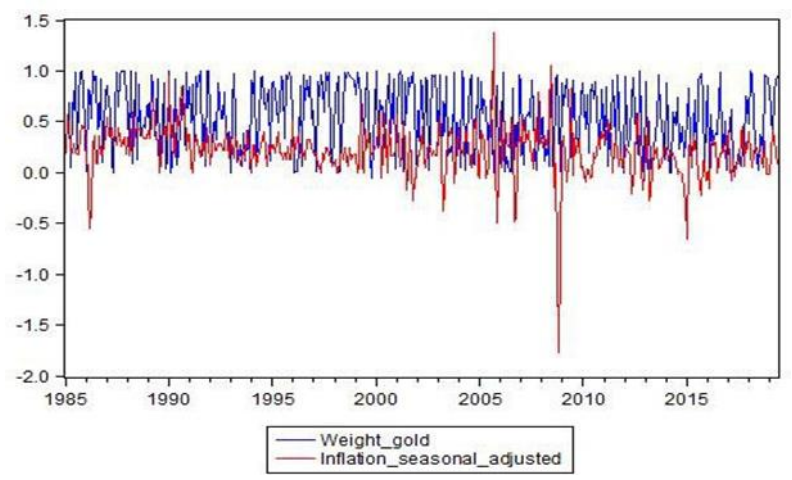

Figure 4. Relation between weight of gold and inflation rate 
We further estimate the slope while employing the dynamic beta computed by Kalman filter as the proxy for gold-inflation hedge (Table 4 ) and another gold-inflation hedge indicator' ${ }_{\text {gold },} / \pi_{t}($ Table 5 ).

Table 4. Regression results with dynamic beta as inflation hedge proxy

\begin{tabular}{|c|c|c|c|}
\hline & \multicolumn{3}{|c|}{ Dependent variable: } \\
\hline & \multicolumn{3}{|c|}{ Weight of gold against SP500 in portfolio } \\
\hline & (1) & $(2)$ & $(3)$ \\
\hline Gold-inflation hedging & $\begin{array}{l}-0.329 \\
(0.330)\end{array}$ & & \\
\hline Gold-inflation_1_lead hedging & & $\begin{array}{l}-26.688 \\
(24.474)\end{array}$ & \\
\hline Gold-inflation_change hedging & & & $\begin{array}{l}-23.789 \\
(23.898)\end{array}$ \\
\hline Interest rate & $\begin{array}{l}-0.001 \\
(0.002)\end{array}$ & $\begin{array}{l}-0.001 \\
(0.002)\end{array}$ & $\begin{array}{l}-0.001 \\
(0.002)\end{array}$ \\
\hline Dummy of recession & $\begin{array}{c}0.079 \\
(0.063)\end{array}$ & $\begin{array}{c}0.082 \\
(0.064)\end{array}$ & $\begin{array}{c}0.084 \\
(0.064)\end{array}$ \\
\hline Dummy of $1985-1995$ & $\begin{array}{c}0.100 \\
(0.062)\end{array}$ & $\begin{array}{l}0.173^{* *} \\
(0.079)\end{array}$ & $\begin{array}{c}0.109^{*} \\
(0.060)\end{array}$ \\
\hline Dummy of $1995-2005$ & $\begin{array}{l}0.161^{* *} \\
(0.067)\end{array}$ & $\begin{array}{l}0.219^{* *} \\
(0.100)\end{array}$ & $\begin{array}{l}0.165^{* *} \\
(0.069)\end{array}$ \\
\hline Dummy of 2005-2015 & $\begin{array}{c}0.025 \\
(0.072)\end{array}$ & $\begin{array}{c}0.033 \\
(0.074)\end{array}$ & $\begin{array}{c}0.024 \\
(0.071)\end{array}$ \\
\hline Constant & $\begin{array}{l}0.895^{* *} \\
(0.432)\end{array}$ & $\begin{array}{c}2.158 \\
(1.550) \\
\end{array}$ & $\begin{array}{c}37.107 \\
(36.807)\end{array}$ \\
\hline Observations & 411 & 411 & 411 \\
\hline $\mathrm{R}^{2}$ & 0.044 & 0.045 & 0.044 \\
\hline Adjusted $\mathrm{R}^{2}$ & 0.030 & 0.031 & 0.030 \\
\hline Residual Std. Error $(\mathrm{df}=404)$ & 0.329 & 0.329 & 0.329 \\
\hline F Statistic $(\mathrm{df}=6 ; 404)$ & $3.125^{* * *}$ & $3.160^{* * *}$ & $3.125^{* * *}$ \\
\hline
\end{tabular}

Note. ${ }^{*} \mathrm{p}<0.1 ; * * \mathrm{p}<0.05 ; * * * \mathrm{p}<0.01$

Table 5. Regression results with the 'peg' proxy

\begin{tabular}{|c|c|c|c|}
\hline & \multicolumn{3}{|c|}{ Dependent variable: } \\
\hline & \multicolumn{3}{|c|}{ Weight of gold against SP500 in portfolio } \\
\hline & $(1)$ & $(2)$ & (3) \\
\hline $\mathrm{R}_{\text {gold }} / \pi_{t}$ & $\begin{array}{c}0.0002 \\
(0.0003)\end{array}$ & & \\
\hline $\mathrm{R}_{\text {gold }} / \pi_{t+1}$ & & $\begin{array}{c}-0.001 \\
(0.0004)\end{array}$ & \\
\hline $\mathrm{R}_{\text {gold }} /\left(\pi_{t}-\pi_{t-1}\right)$ & & & $\begin{array}{l}-0.00000 \\
(0.00000)\end{array}$ \\
\hline US dollar & $\begin{array}{l}-0.002 \\
(0.014)\end{array}$ & $\begin{array}{l}-0.006 \\
(0.014)\end{array}$ & $\begin{array}{l}-0.003 \\
(0.014)\end{array}$ \\
\hline Interest rate & $\begin{array}{l}-0.001 \\
(0.002)\end{array}$ & $\begin{array}{l}-0.001 \\
(0.002)\end{array}$ & $\begin{array}{l}-0.001 \\
(0.002)\end{array}$ \\
\hline Dummy of recession & $\begin{array}{c}0.061 \\
(0.067)\end{array}$ & $\begin{array}{c}0.055 \\
(0.068)\end{array}$ & $\begin{array}{c}0.065 \\
(0.067)\end{array}$ \\
\hline Dummy of $1985-1995$ & $\begin{array}{l}0.114^{*} \\
(0.061)\end{array}$ & $\begin{array}{l}0.125^{* *} \\
(0.060)\end{array}$ & $\begin{array}{l}0.118^{*} \\
(0.060)\end{array}$ \\
\hline Dummy of $1995-2005$ & $\begin{array}{l}0.108^{*} \\
(0.062)\end{array}$ & $\begin{array}{l}0.120^{*} \\
(0.062)\end{array}$ & $\begin{array}{l}0.114^{*} \\
(0.062)\end{array}$ \\
\hline Dummy of 2005-2015 & $\begin{array}{l}-0.022 \\
(0.062)\end{array}$ & $\begin{array}{l}-0.009 \\
(0.062)\end{array}$ & $\begin{array}{l}-0.017 \\
(0.062)\end{array}$ \\
\hline Constant & $\begin{array}{c}0.475^{* * *} \\
(0.053)\end{array}$ & $\begin{array}{c}0.465^{* * *} \\
(0.052)\end{array}$ & $\begin{array}{c}0.470^{* * *} \\
(0.052)\end{array}$ \\
\hline Observations & 386 & 386 & 386 \\
\hline $\mathrm{R}^{2}$ & 0.041 & 0.044 & 0.040 \\
\hline Adjusted $\mathrm{R}^{2}$ & 0.023 & 0.026 & 0.022 \\
\hline Residual Std. Error $(\mathrm{df}=378)$ & 0.331 & 0.331 & 0.331 \\
\hline$\underline{\text { F Statistic }(\mathrm{df}=7 ; 378)}$ & $2.293^{* *}$ & $2.489^{* *}$ & $2.238^{* *}$ \\
\hline
\end{tabular}

Note. ${ }^{*} \mathrm{p}<0.1 ; * * \mathrm{p}<0.05 ; * * * \mathrm{p}<0.01$.

As we can see, no matter what proxy we employ for gold-inflation hedge, no statistical evidence can be found to indicate any valid agreement on the dynamics of co-movement between gold-stock hedge and gold-inflation hedge. The slopes are not positive which imply that hedge coefficients of gold against stock do not move in tandem with inflation or the specified form of inflation. Based on the outcomes of Table 3, 4, and 5, gold is infeasible to hedge stock market and inflation simultaneously in our framework.

Overall, all the three specifications and estimations on second stage fail to pinpoint any possibility that investors can still beat inflation when assuming they use gold to optimally hedge equity market represented by SP500 first through adjusting the weight of gold they hold by month. This result is opposite but not contradictory to the implication of our baseline regression of comparison. 


\section{Discussion and Conclusion}

This is the first paper addressing whether gold can hedge stock market and inflation in a simultaneous content, particularly, from the perspective of investor and portfolio manager. Previous studies have greatly explored the hedging property of gold against single asset like stock or inflation, while this paper offers a more comprehensive view on the hedging usage of gold in the scenario where the hedging objects have potential conflicts in their performance dynamics which triggers the failure of valid and simultaneous hedge by gold.

In this work, we assume that an investor creates optimal portfolios from stock and gold. The weights assigned to gold are interpreted as hedge coefficient towards the stock market. We ask if the hedge coefficient also moves in tandem with inflation or other functions of inflation or gold-inflation hedge proxy. When regressing the hedge coefficient on inflation or functions of inflation, the slope will be positive if the gold 'first' used to hedge the stock market can also hedge inflation. We find that is not the case: the coefficient is not positive in statistics. This result implies that gold fails to hedge both stock market and inflation simultaneously over time, and it is opposite but not contradictory to the implication of baseline regression of comparison which suggests gold can hedge stock market and inflation together in the long run if investors hold gold from beginning to the end without any action of selling or re-balancing portfolio. The difference is that, under our context of simultaneity, the active and efficient hedging strategy conducted through gold could only target one subject of interest, either stock market or inflation, at each moment of the sample period. Except addressing the puzzle we try to visit, the other contribution of our work is that we provide future study with a new approach and framework to address the issue of simultaneity in investment or asset management problem, and creating the room for future work to emphasize different perspective of similar question or puzzle.

Even though this paper does not aim to identify the causality of gold's failure to simultaneous hedge, there are some reasonable explanations as the candidates for causality. As the fact that stock market boom frequently comes with moderate inflation has been greatly verified in literature, one of the most convincing explanations is that the dynamics of gold prices becomes ambiguous and unclear on the moments where moderate inflation and stock rise occur together and the unclear dynamics further forbids the hedging property of gold against either equity market or inflation or both on those moments. Another explanation is that the proxy of gold-stock hedge in this paper considers the scenario that investors 'optimally' use gold to hedge equity asset (SP500) so that the computed hedge coefficients for gold-stock hedge might be not sufficiently 'friendly' to agree on hedging inflation or other dynamics of inflation in tandem. In that sense, if we incorporate more 'inflation-friendly' objective function for the portfolio optimization problem in first stage, the estimates might differ, and it may enable our approach to generate a situation that gold can hedge stock market and inflation simultaneously to a certain degree although such degree is expected to be very limited.

\section{Acknowledgments}

I am grateful to the valuable comments made by Xiangyu (Anthony) Zhang, Xiaolin Sun, and two anonymous referees. I thank the excellent teaching by faculty of economics at Simon Fraser University in Vancouver, Canada where I had the most unforgettable memory. All errors in this paper are, of course, on my own.

\section{References}

Areal, N., Benilde, O., \& Raquel, S. (2013). When times Get Tough, Gold Is Golden. The European Journal of Finance, 1-20. https://doi.org/10.1080/1351847X.2013.854821

Batten, J. A., Cetin, C., \& Brian, M. L. (2014). On the Economic Determinants of the Goldinflation Relation. Resources Policy, 41(2014), 101-08. https://doi.org/10.1016/j.resourpol.2014.03.007

Baur, D. G. (2012). Asymmetric Volatility in the Gold Market. The Journal of Alternative Investments. https://doi.org/10.3905/jai.2012.14.4.026

Baur, D. G., \& Thomas, K. M. (2010). Is Gold a Safe Haven? International Evidence. Journal of Banking Finance, 34(8), 1886-898. https://doi.org/10.1016/j.jbankfin.2009.12.008

Baur, D., \& Brian, L. (2007). Is Gold a Hedge or a Safe Haven? An Analysis of Stocks, Bonds and Gold. IDEAS Working Paper Series from RePEc, 2007.

Beckmann, J., \& Robert, C. (2013). Gold as an Inflation Hedge in a Time-varying Coefficient Framework. The North American Journal of Economics and Finance, 24, 208-22. https://doi.org/10.1016/j.najef.2012.10.007

Brown, W. O., Dayong, H., \& Fang, W. (2016). Inflation Illusion and Stock Returns. Journal of Empirical Finance, 35, 14-24. https://doi.org/10.1016/j.jempfin.2015.11.001

ChristieDavid, R., Mukesh, C., \& Timothy, W. K. (2000). Do Macroeconomics News Releases Affect Gold and 
Silver Prices? Journal of Economics and Business, 52(5), $405-21$. https://doi.org/10.1016/S0148-6195(00)00029-1

Emmrich, O., \& Francis, J. M. (2013). Should Gold Be Included in Institutional Investment Portfolios? Applied Financial Economics, 23(19), 1553-565. https://doi.org/10.1080/09603107.2013.839858

Engle, R. (2002). Dynamic Conditional Correlation. Journal of Business Economic Statistics, 20(3), 339-50. https://doi.org/10.1198/073500102288618487

Kaul, G. (1987). Stock returns and inflation : The role of the monetary sector. Journal of Financial Economics, 18(2), 253-276. https://doi.org/10.1016/0304-405X(87)90041-9

Markowitz, H. (1952). Portfolio Selection. The Journal of Finance, 7(1), 77-91. https://doi.org/10.1111/j.1540-6261.1952.tb01525.x

Neill, F. J. (1987). The Inflation Rate of the Price of Gold, Expected Prices and Interest Rates. Journal of Macroeconomics, 9(1), 71-82. https://doi.org/10.1016/S0164-0704(87)80007-1

Qi, M., \& Wenyao, W. (2013). The Monthly Effects in Chinese Gold Market. International Journal of Economics and Finance, 5(10), 141-146. https://doi.org/10.5539/ijef.v5n10p141

Smales, L. A. (2014). News Sentiment in the Gold Futures Market. Journal of Banking Finance, 49, $275-86$. https://doi.org/10.1016/j.jbankfin.2014.09.006

Smales, L. A., \& Yi, Y. (2015). The Importance of Belief Dispersion in the Response of Gold Futures to Macroeconomic Announcements. International Review of Financial Analysis, 41(2015), $292-302$. https://doi.org/10.1016/j.irfa.2015.01.017

Worthington, A. C., \& Mosayeb, P. (2007). Gold Investment as an Inflationary Hedge: Cointegration Evidence with Allowance for Endogenous Structural Breaks. Applied Financial Economics Letters, 3(4), $259-62$. https://doi.org/10.1080/17446540601118301

Yin-Wong, C., \& Kon, S. L. (1993). Do Gold Market Returns Have Long Memory? The Financial Review, 28(2), 181-202. https://doi.org/10.1111/j.1540-6288.1993.tb01344.x

\section{Copyrights}

Copyright for this article is retained by the author(s), with first publication rights granted to the journal.

This is an open-access article distributed under the terms and conditions of the Creative Commons Attribution license (http://creativecommons.org/licenses/by/4.0/). 